\title{
Familial hypercholesterolaemia in Portugal
}

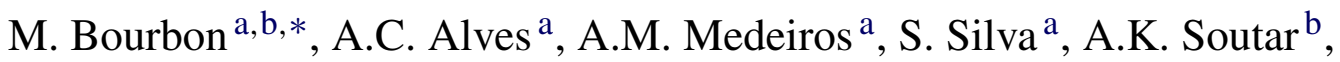 \\ on behalf of the investigators of the Portuguese FH study ${ }^{1}$ \\ ${ }^{a}$ Unid. Investigação Cardiovascular, Inst. Nacional de Saúde, Lisbon, Portugal \\ ${ }^{\mathrm{b}}$ MRC Lipoprotein Group, Clinical Sciences Centre, Hammersmith Hospital, London, UK \\ Received 16 April 2007; received in revised form 19 June 2007; accepted 11 July 2007 \\ Available online 31 August 2007
}

\begin{abstract}
Familial hypercholesterolaemia (FH) is characterised clinically by an increased level of circulating LDL cholesterol that leads to lipid accumulation in tendons and arteries, premature atherosclerosis and increased risk of coronary heart disease (CHD). Although Portugal should have about 20,000 cases, this disease is severely under-diagnosed in our country, this being the first presentation of Portuguese data on FH. A total of 602 blood samples were collected from 184 index patients and 418 relatives from several centres throughout Portugal. Fifty-three different mutations were found in 83 index patients, 79 heterozygous and 4 with two defective LDLR alleles. Additionally, 4 putative alterations were found in 8 patients but were not considered mutations causing disease, mainly because they did not co-segregate with hypercholesterolaemia in the families. Three unrelated patients were found to be heterozygous for the APOB 3500 mutation and two unrelated patients were found to be heterozygous for a novel mutation in PCSK9, predicted to cause a single amino acid substitution, D374H. Cascade screening increased the number of FH patients identified genetically to 204. The newly identified FH patients are now receiving counselling and treatment based on the genetic diagnosis. The early identification of FH patients can increase their life expectancy and quality of life by preventing the development of premature CHD if patients receive appropriate pharmacological treatment.
\end{abstract}

(C) 2007 Elsevier Ireland Ltd. All rights reserved.

Keywords: Familial hypercholesterolaemia; Low density lipoprotein receptor; Mutations; Coronary heart disease; Index patient; Cholesterol

\footnotetext{
* Corresponding author at: Unid. Investigação Cardiovascular, Inst. Nacional de Saúde, Lisbon, Portugal. Tel.: +351 217526 476; fax: +351217526 400 .

E-mail address: mafalda.bourbon@insa.min-saude.pt (M. Bourbon).

1 "The Portuguese Familial Hypercholesterolaemia Study" is being developed at the Unidade de Investigação Cardiovascular, Centro de Biopatologia, Instituto Nacional de Saúde Dr. Ricardo Jorge (INSA). Coordinator: Dr. Mafalda Bourbon. Clinical consultant: Dr. Quitéria Rato. Molecular research: Dr. Mafalda Bourbon (principal investigator), Ana Catarina Alves, Ana Margarida Medeiros and Sónia Silva, Unidade de Investigação Cardiovascular, CBP, INSA. Clinical reseach: Prof. António Guerra, Serv. de Pediatria, Hosp. de S. João, E.P.E., Porto; Dr. António Furtado, Serv. de Med. Interna, Hosp. Pedro Hispano, Matosinhos; Prof. José Manuel Silva, Serv. de Med. Interna, HUC, Coimbra; Dr. António Cruz, Serv. Pediatria, Hosp. Sto André, Leiria; Dr. Lina Cardoso Ramos, Serv. Genética, Dr. Paula Garcia, Unid. Doenças Metabólicas, Hosp. Pediátrico, Coimbra; Dr. Isabel Gaspar, Serv. de Genética, Dr. Ana Gaspar, Serv Pediatria, Hosp. de Santa Maria, E.P.E., Lisboa; Prof. Graça Morais, Dept. de Bioquímica, Fac. de
}

\section{Introduction}

Familial hypercholesterolaemia (FH) is an autosomal dominant disorder with a frequency of about $1 / 500$ in most European countries [1]. FH usually results from inherited

Ciências Médicas, UNL, Lisboa; Prof. Heloísa Santos, Fundação Professor Fernando de Pádua, Lisboa; Dr. Pedro Marques da Silva, Serv. de Med. Interna, Hosp. de Santa Marta, E.P.E, Lisboa; Dr. João Sequeira Duarte, Serv. de Endocrinologia, Hosp. de Egas Moniz, Lisboa; Dr. Leonor Sassetti, Unid. de Adolescentes, Dr. Sílvia Sequeira, Serv. Doenças Metabólicas, Hosp. D. Estefânia, Lisboa; Dr. Piedade Sande Lemos, Serv Pediatria, Hosp Amadora Sintra, Amadora; Dr. Renata Rossi, Serv. Cardiologia Pediátrica, Dr. Margarida Bruges Serv Nefrologia, Hosp. Sta. Cruz, Carnaxide; Dr. Mário Amaro, Serv Medicina Interna, Hospital Garcia da Orta, Almada; Dr. Quitéria Rato, Serv. de Cardiologia, CHS, Hosp. de São Bernardo, Setúbal; Dr. M ${ }^{a}-$ Luísa Gonçalves, Serv. Medicina Interna, Hosp. Litoral Alentejano, Santiago do Cacém; Dr. Isabel Azevedo, Serv. de Med. Interna I, Hosp. dos Marmeleiros, Funchal. 
defects in the low density lipoprotein receptor gene $(L D L R)$ but mutations in the gene for apolipoprotein $\mathrm{B}(A P O B)$ or, more recently described, mutations in the proprotein convertase subtilisin/Kexin type 9 (PCSK9) gene also cause the same phenotype. FH is clinically characterised by an increased level of circulating LDL cholesterol that leads to lipid accumulation in tendons (xanthomas) and arteries, premature atherosclerosis and increased risk of coronary heart disease (CHD). Although Portugal should have about 20,000 cases, this disease is severely under-diagnosed in our country where no prior clinical or genetic studies have been performed. Men and women with FH aged between 20 and 39 years old have an 100-fold increased risk to develop premature CHD compared to the normal population [2]. It is important to identify as early as possible individuals with FH to improve their prognosis by administration of appropriate therapeutic interventions and also to allow provision of genetic counselling and to ensure access to specialised medical services. The aim of this project was to set up a network of lipid clinics and an analytical laboratory for the "Portuguese FH study" [3] and perform the molecular characterization of patients with a clinical diagnosis of Familial hypercholesterolaemia $(\mathrm{FH})$ to allow cascade screening of the relatives of index patients. It was also expected that comparison of the clinical and molecular characteristics of Portuguese FH patients with $\mathrm{FH}$ patients from other countries may provide some insight about the underlying reason for the different severity of the phenotypes presented by FH patients.

\section{Methods}

\subsection{Patient recruitment}

A total of 602 blood samples were collected from 184 index patients and 418 relatives of 124 of these families.
The 184 index patients, 51 children (aged 18-year old or under) and 133 adults, were referred to our institute by 21 clinicians working in public hospitals, mainly in cardiology, internal medicine, paediatric and genetic services, throughout the country and islands (Fig. 1). A clinical questionnaire adapted from the "Simon Broome Heart Research Study" [4] was completed by clinicians for each index patient and informed consent was signed by all index patients and relatives. For children under 18 the declaration was signed by the parents.

\subsection{Biochemical characterization}

The biochemical parameters including total cholesterol, HDL cholesterol, triglycerides, apolipoprotein AI, apolipoprotein B and lipoprotein (a), were determined for all subjects in an Hitachi 911 (Boehringer Mannheim, Roche) by an enzymatic colorimetric method, following the manufacturer's instructions. LDL cholesterol values were calculated using the Friedewald formula.

\subsection{DNA analysis}

Amplified fragments from genomic DNA comprising all exons of the LDLR gene, were analysed for mutations by highly sensitive denaturing high pressure liquid chromatography (DHPLC) (Transgenomics, USA) and automated sequencing. Large rearrangements in the LDLR were identified by multiplex ligation-dependent probe amplification (MLPA) with the kit for the LDLR gene (SALSA P062B kit) from MRC-Holland (Amsterdam, The Netherlands), following the manufacturer's instructions. MLPA amplification products were analysed with the GeneScan Analysis Software Version 3.1.2 and peak heights were measured with Genotyper Software Version 2.5 (Applied Biosystems) and exported to excell sheets for further processing. The peak
(A)

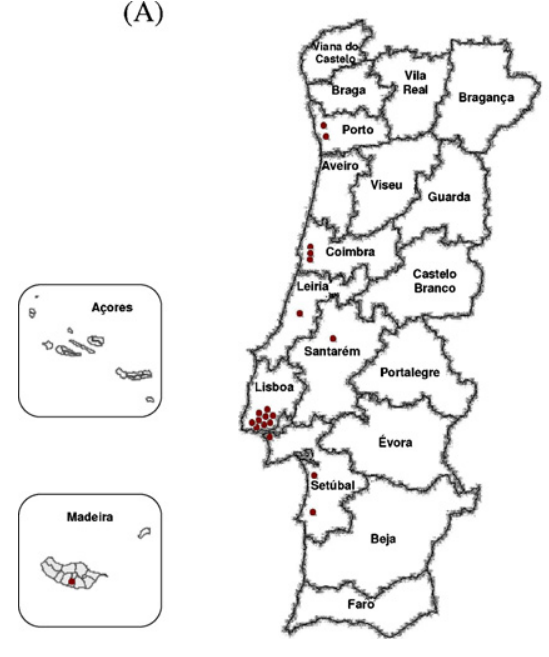

(B)

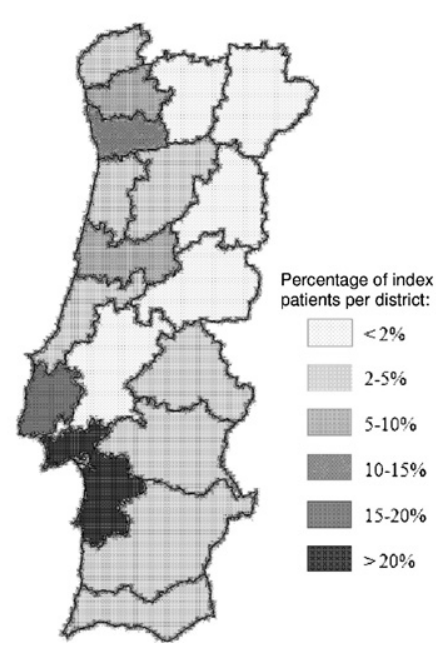

Fig. 1. Demographic distribution of Clinicians and index patients participating in the Portuguese FH study. (A) Portuguese network of clinicians currently collaborating with the Portuguese FH study. (B) Origin of 184 unrelated index patients registered in the Portuguese FH study, by district. 
heights were normalised and then divided by average normalized peaks from four normal control subjects. The results are given as relative allele copy number as compared to normal controls, so a ratio of $\sim 1$ is obtained if both alleles are present, a ratio of $\sim 0.5$ if an allele is absent and $\sim 1.5$ if an allele is duplicated.

APOB gene was analysed by amplification and sequencing of a fragment of exon 26 containing the four most common $A P O B$ mutations and a fragment of exon 29 as described before [5].

All 12 exons of PCSK9 gene were amplified and sequenced as described before [6]

\subsection{LDLR and APOB gene haplotyping}

$L D L R$ haplotypes were analysed by PCR amplification and sequencing of fragments containing known common variants in this gene namely, $81 \mathrm{~T}>\mathrm{C}(\mathrm{SfaNI}), 1060+10 \mathrm{G}>\mathrm{C}$ (SmaI), 1171G $>$ A (StuI), 1413G $>$ A $($ BsmAI), 1617C $>$ T (BstNI), $1773 \mathrm{C}>\mathrm{T}$ (HincII), $1959 \mathrm{~T}>\mathrm{C}$ (AvaII), 2232G $>\mathrm{A}$ (MspI), $2389+46,2547-80,2547-42$ and $2583+52$, corresponding to exon 2 , intron 7 , exons $8,9,11-13,15$, intron 16,17 and $3^{\prime} \mathrm{UTR}$ region.

$A P O B$ haplotypes of patients with the $A P O B_{3500}$ mutation were determined by PCR amplification and restriction analysis and/or sequencing of four polymorphic sites in the APOB gene, as described previously $[7,8]$

\subsection{Long-range PCR}

For PCR amplification of large fragments of the LDLR gene, Expand Long Template PCR System was used according to manufacturer's instructions (Roche Applied Science). The reactions were carried out in a Biometra T3000 thermocycler (Germany). The fragments obtained were analysed by direct sequencing.

\subsection{Analysis of human single tandem repeats}

Single tandem repeats (STR) analysis was performed as a test for paternity using the AmpFlSTR ${ }^{\circledR}$ Profiler Plus ${ }^{\mathrm{TM}}$ following manufacturer's instructions (Applied Biosystems, USA). The products obtained were analysed with the Genemapper Software Version 3.7 (Applied Biosystems)

All sequencing reactions, MLPA reactions and STR analysis described here were analysed in a 3100 Genetic Analyser with 16 capillaries (Applied Biosystems, USA) using POP6 polymer according to the manufacturer's instructions. PCR conditions and primers are available on request.

\subsection{Statistical analysis}

All data were analysed with SPSS software (version 13.0). To test for association between variables, the Pearson Chi square test and the Fisher exact test were used. When these could not be applied, non-parametric tests were used: Mann-Whitney (for two independent samples) and Kruskall-Wallis (for more than two independent samples). For all tests used $p<0.05$ was considered statistically significant.

\section{Results}

\subsection{Clinical data analysis}

The clinical and biochemical characteristics and relevant life habits of the 184 Portuguese FH patients are summarized in Table 1.

\subsection{Molecular analysis}

\subsection{1. $L D L R$}

Fifty-three different mutations were found in 83 index patients, 23 of which have not been described previously (Table $2 \mathrm{a}$ ). These include 31 point mutation, 3 nonsense mutations, 6 splice site mutations, 11 small deletions and insertions and 2 large deletions. Additionally, 2 alterations, 2 missense and 2 potential splicing alterations, were found in 8 index patients (Table 2b) where in all but one, other mutations have not been found in APOB, LDLR or PCSK9. The pathogenicity of these alterations is not clear, mainly due to lack of co-segregation of the alteration with hypercholesterolaemia in the family. One of these alterations, G248D, has been described before as a mutation causing disease (online FH database: www.ucl.ac.uk/fh) but it did not co-segregate with the hypercholesterolaemia in one of the three different families where this alteration was found. In fact in this family this alteration was not present in two hypercholesterolaemic relatives and it was found in two normolipidaemic relatives. This suggests that this variant has no deleterious effect on LDL receptor function. Another alteration, $818-2 \mathrm{~A} / \mathrm{G}$, was identified in this family that co-segregates with the hypercholesterolaemia in this family (Fig. 2A) and was for this reason considered the mutation causing disease.

Four patients were found to carry two defective LDLR alleles, even though three of these patients did not present a typical "homozygous" phenotype (Table 3): one homozygous for V408L, one homozygous for A410T and one compound heterozygous for A410T and a potential splicing mutation $313+6 \mathrm{~T} / \mathrm{C}$. The compound heterozygous patient inherited the $313+6 \mathrm{~T} / \mathrm{C}$ mutation from her father but the A410T mutation has appeared de novo in her maternal allele and she transmitted it to her two sons. This result was confirmed by the analysis of human STRs (data not shown) that proved that the mother was indeed the biological mother.

Patients in whom no mutation in the LDLR or APOB genes could be identified by dHPLC and/or sequencing were analysed by MLPA to search for large rearrangements in the LDLR gene. Two large deletions were found by MLPA in three unrelated patients with a severe $\mathrm{FH}$ phenotype; one index patient was found to carry an allele with deletion of 
Table 1

Patient distribution in the paediatric and adult groups. Clinical and biochemical characteristics, smoking and alcohol consumption habits percentages

\begin{tabular}{|c|c|c|c|c|}
\hline & Paediatric (under 18) & $n$ & Adults & $n$ \\
\hline Age (years) & $9.98 \pm 3.89$ & 51 & $46.63 \pm 13.82$ & 130 \\
\hline BMI $\left(\mathrm{kg} / \mathrm{m}^{2}\right)$ & $19.92 \pm 3.45$ & 51 & $26.11 \pm 4.95$ & 119 \\
\hline Female $(\%)$ & 54.9 & 28 & 60.9 & 81 \\
\hline Male $(\%)$ & 45.1 & 23 & 39.1 & 52 \\
\hline \multirow[t]{2}{*}{ Total cholesterol (mg/dl) } & $297.95 \pm 7.84^{\mathrm{a}}$ & 46 & $361.72 \pm 84.55$ & 89 \\
\hline & $248 \pm 53.19^{b}$ & 46 & $279 \pm 81.5$ & 115 \\
\hline \multirow[t]{2}{*}{ LDL cholesterol (mg/dl) } & $221.53 \pm 66.69^{\mathrm{a}}$ & 40 & $276.01 \pm 85.82$ & 75 \\
\hline & $168 \pm 48.74^{b}$ & 46 & $209 \pm 191.36$ & 115 \\
\hline \multirow[t]{2}{*}{ HDL cholesterol (mg/dl) } & $56.05 \pm 17.90^{\mathrm{a}}$ & 40 & $52.47 \pm 15.08$ & 79 \\
\hline & $58 \pm 15.56^{\mathrm{b}}$ & 46 & $57 \pm 15.35$ & 115 \\
\hline \multirow[t]{2}{*}{ Triglycerides (mg/dl) } & $110.29 \pm 76.69^{\mathrm{a}}$ & 42 & $162.61 \pm 114.59$ & 81 \\
\hline & $111 \pm 67.54^{\mathrm{b}}$ & 46 & $153 \pm 110.14$ & 115 \\
\hline ApoB (mg/dl) & $109.23 \pm 55.58^{\mathrm{b}}$ & 46 & $147.32 \pm 67.22$ & 115 \\
\hline ApoAI (mg/dl) & $136.08 \pm 34.95^{\mathrm{b}}$ & 46 & $138.74 \pm 35.11$ & 115 \\
\hline $\mathrm{Lp}(\mathrm{a})(\mathrm{mg} / \mathrm{dl})$ & $73.45 \pm 80.01^{\mathrm{b}}$ & 45 & $65.41 \pm 65.03$ & 111 \\
\hline Alcohol consumption (\%) & 2.0 & 1 & 36.8 & 46 \\
\hline Smokers (\%) & 2.0 & 1 & 15.0 & 19 \\
\hline Hypertension (\%) & 2.0 & 1 & 28.7 & 37 \\
\hline Diabetes $(\%)$ & 0.0 & 0 & 1.6 & 2 \\
\hline Thyroid (\%) & 0.0 & 0 & 4.7 & 6 \\
\hline Tendon xanthomas (\%) & 0.0 & 0 & 8.5 & 11 \\
\hline $\mathrm{CHD}(\%)^{\mathrm{c}}$ & 0.0 & 0 & 25.4 & 33 \\
\hline On medication $(\%)^{\mathrm{d}}$ & 34 & 17 & 88.8 & 111 \\
\hline Exercise (\%) & 56.0 & 28 & 39.5 & 49 \\
\hline
\end{tabular}

${ }^{\mathrm{a}}$ Values before medication. Not available for all individuals.

b Values at present time, most under medication; only obtained for 161/184 index patients.

${ }^{c} \mathrm{CHD}$ is considered angina, coronary artery bypass graft (CABG) and miocardial infarction.

${ }^{\mathrm{d}}$ Medication is considered statins, fibrates, eztimibe and resins in the paediatric group.

exons $8-12$ and, the other two patients, carried a deletion of the $5^{\prime}$-end of the LDLR gene, comprising the promoter, exons 1 and 2, plus the deletion of exons 8-12, as showed in Fig. 3 for one of the patients. These mutations were also found in relatives of these index patients. In individuals that showed half the normal copy number of exons 8-12, the deletion of these five exons was confirmed by long-range PCR (Fig. 3C). The pattern of inheritance in the family indicated that both deletions occurred on the same allele. The haplotype analysis of these three patients revealed that they share the same haplotype for the mutant allele: C (1060+1), G (2232), C (2389 +46), G (2547 -80), G (2547 -42).

The most common mutation, A410T, represents $13 \%$ of all genetically identified FH cases in this study and only two different haplotypes have been found: C (81, SfaNI), C (1060 +10, SmaI), G (1171, StuI), G (1413, BsmAI), C (1617, BstNI), T (1773 HincII), C (1959, AvaII), G (MspI) and C (81, SfaNI), G $(1060+10$, SmaI), G (1171, StuI), A (1413, BsmAI), C (1617, BstNI), C(1773 HincII), T (1959, AvaII), G (MspI).

\subsection{2. $A P O B$}

Three unrelated patients with clinical diagnosis of $\mathrm{FH}$ were found to be heterozygous for the R3500Q mutation in the APOB gene. The mutation was also found in three hypercholesterolaemic relatives of these patients. The genotypes for four $A P O B$ polymorphic sites were determined in these individuals. The R3500Q allele was associated with the haplotype PvuII-/XbaI-/MspI+/EcoRI- in the three families although we did not have relatives of the third family and so this haplotype is only estimated. These are the first $\mathrm{APOB}_{3500}$ patients to be described in the Portuguese population and carry the same Caucasian haplotype as described before [7]

\subsubsection{PCSK9}

Two unrelated patients and one relative were found to be heterozygous for a novel mutation in PCSK9, predicted to cause a single amino acid substitution, D374H. These patients presented a very severe phenotype with extremely high total cholesterol levels, mean value of $505.40 \pm 86.82 \mathrm{mg} / \mathrm{dl}$ versus other FH patients with mean value of $353.93 \pm 83.0 \mathrm{mg} / \mathrm{dl}$ (LDLR) and $279.54 \pm 52.97 \mathrm{mg} / \mathrm{dl}$ (APOB), and several relatives with premature CHD (Fig. 4 in supplement). Total cholesterol values in PCSK9 patients were significantly different from those in LDLR and APOB patients $(p=0.034$; $p=0.022$ ). This mutation has not been reported before, but a different nucleotide substitution in the same codon has been described in four English patients (D374Y) who also had a very severe phenotype [9].

\subsection{Cascade screening}

Screening of 206 relatives in families of 88 index patients, 19 children (under 18) and 69 adults, lead to the identification of 116 additional genetically diagnosed FH patients, 27 
Table 2a

Mutations found in the LDLR gene

\begin{tabular}{|c|c|c|c|}
\hline Nucleotide change & Predicted effect & No of index patients & No of relatives \\
\hline c. $-21 \mathrm{~A}>\mathrm{C}$ & $\mathrm{M}-21 \mathrm{~L}$ in signal peptide & 1 & 0 \\
\hline [Pr_EX2del + EX8_12del] & Large deletion of 7 exons & 1 & 8 \\
\hline c.226G $>\mathrm{T}$ & G55W in ligand binding domain & 1 & 3 \\
\hline c. $241 \mathrm{C}>\mathrm{T}$ & R60C in ligand binding domain & 1 & 0 \\
\hline c. $265 \mathrm{~T}>\mathrm{C}$ & C68R in ligand binding domain & 1 & 2 \\
\hline c.292G $>C$ & G77R in ligand binding domain & 1 & $\mathbf{0}$ \\
\hline c. $313+1 \mathrm{G}>\mathrm{A}$ & Splicing error & 1 & 0 \\
\hline c. $313+6 \mathrm{~T}>\mathrm{C}$ & Splicing error & 1 & 1 \\
\hline c. $326 \mathrm{G}>\mathrm{T}$ & $\mathrm{C} 88 \mathrm{~F}$ in ligand binding domain & 1 & 3 \\
\hline c.369_393del25 & S102fsX176 & 1 & 1 \\
\hline c. $530 \mathrm{C}>\mathrm{T}$ & S156L in ligand binding domain & 3 & 7 \\
\hline c. $551 \mathrm{G}>\mathrm{A}$ & $\mathrm{C} 163 \mathrm{Y}$ in ligand binding domain & 1 & 3 \\
\hline c.619_639del21 & In frame. G186_S192del & 1 & 2 \\
\hline c. $631 \mathrm{C}>\mathrm{G}$ & H190D in ligand binding domain & 1 & $\mathbf{0}$ \\
\hline c. $661 \mathrm{G}>\mathrm{T}$ & D200Y in ligand binding domain & 1 & 1 \\
\hline c. $662 \mathrm{~A}>\mathrm{G}$ & D200G in ligand binding domain & 1 & 1 \\
\hline c. $682 \mathrm{G}>\mathrm{A}$ & D203N in ligand binding domain & 7 & 14 \\
\hline c. $670 \mathrm{G}>\mathrm{A}$ & E207K in ligand binding domain & 1 & 0 \\
\hline c.818 $-2 A>G$ & Splicing error & 2 & 4 \\
\hline c. $862 \mathrm{G}>\mathrm{A}$ & E267K in ligand binding domain & 1 & 0 \\
\hline c.1016_1017insG & L318fsX336 & 1 & 3 \\
\hline c. $1027 \mathrm{G}>\mathrm{A}$ & G322S in EGF precursor homology domain & 1 & 1 \\
\hline c. $1031 \mathrm{C}>\mathrm{T}$ & Stop codon. Q324X & 1 & 3 \\
\hline c. $1048 \mathrm{C}>\mathrm{T}$ & Stop codon. R329X & 1 & 0 \\
\hline c. $1060+1 \mathrm{G}>\mathrm{A}$ & Splicing error & 2 & 0 \\
\hline c.1085delA & D341fsX348 & 1 & 1 \\
\hline c.1178delA & K372fsX392 & 1 & $\mathbf{0}$ \\
\hline EX8_12del & Large deletion of 5 exons & 1 & 4 \\
\hline c. $1216 \mathrm{C}>\mathrm{T}$ & $\mathrm{R} 385 \mathrm{~W}$ in EGF precursor homology domain & 4 & 9 \\
\hline c. $1222 \mathrm{G}>\mathrm{A}$ & E387K in EGF precursos homology domain & 1 & 0 \\
\hline c. $1285 G>C$ & V408L in EGF precursor homology domain & 1 & $\mathbf{0}$ \\
\hline c. $1291 \mathrm{G}>\mathrm{A}$ & A410T in EGF precursor homology domain & 11 & 14 \\
\hline c. $1432 \mathrm{G}>\mathrm{A}$ & G457R in EGF precursor homology domain & 2 & 4 \\
\hline c. $1455 C>G$ & H464Q in EGF precursos homology domain & 1 & 1 \\
\hline c.1468T $>C$ & W469R in EGF precursor homology domain & 1 & 3 \\
\hline c. $1633 G>T$ & G524W in EGF precursor homology domain & 1 & 1 \\
\hline c.1659_1661delCTCinsATACTTTCA & Stop codon. Y532X & 1 & 1 \\
\hline c. $1690 \mathrm{~A}>\mathrm{C}$ & $\mathrm{N} 543 \mathrm{H}$ in EGF precursor homology domain & 1 & 0 \\
\hline c. $1775 \mathrm{G}>\mathrm{A}$ & G571E in EGF precursor homology domain & 3 & 4 \\
\hline c. $1816 \mathrm{G}>\mathrm{T}$ & A585S in EGF precursor homology domain & 3 & 0 \\
\hline c.1840T $>\mathrm{A}$ & F593I in EGF precursor homology domain & 1 & 1 \\
\hline c.1845+1delG & Splicing error & 1 & $\mathbf{0}$ \\
\hline c.1886delT & F608fsX642 & 1 & $\mathbf{0}$ \\
\hline c.1935_1936delA & N624fsX646 & 1 & 1 \\
\hline c.1942T $>C$ & S627P in EGF precursor homology domain & 1 & $\mathbf{0}$ \\
\hline c.1999T >C & C646R in EGF precursor homology domain & 1 & 0 \\
\hline c. $2053 \mathrm{C}>\mathrm{T}$ & P664S in EGF precursor homology domain & 1 & 0 \\
\hline c. $2056 \mathrm{C}>\mathrm{T}$ & Stop codon. Q665X & 1 & 3 \\
\hline c.2077_2078delAA & K672fsX694 & 1 & 1 \\
\hline c. $2389 \mathrm{G}>\mathrm{A}$ & V776M in membrane spanning domain & 1 & 5 \\
\hline c.2399_2403delTCTTCinsGGGT & V779fsX910 & 1 & 0 \\
\hline c.2417_2418insG & V785fsX795 & 1 & 0 \\
\hline c. $2547+1 G>A$ & Splicing error & 2 & 2 \\
\hline
\end{tabular}

Novel mutations are in bold. 
Table $2 b$

Putative mutations causing disease found in the LDLR gene

\begin{tabular}{llll}
\hline Nucleotide change & Predicted effect & No index patients & No relatives \\
\hline c. $806 \mathrm{G}>\mathrm{A}$ & G248D in ligand binding domain & 4 & 6 \\
c.1061 $-8 \mathrm{~T}>\mathrm{C}$ & Splicing error? & 1 & 7 \\
c.1359 $-\mathbf{5 C}>\mathbf{G}$ & Splicing error? & $\mathbf{2}$ & $\mathbf{3}$ \\
c.2575G $>$ A & V838M in internalisation signal domain & $\mathbf{1}$ & $\mathbf{1}$
\end{tabular}

Novel alterations are in bold.

children and 89 adults, making a total of 46 children and 158 adults genetically identified as having $\mathrm{FH}$.

\subsection{Patients with no mutations in $L D L R, A P O B$ and PCSK9 genes}

No alteration could be found in the LDLR, APOB gene or PCSK9 gene of 88 patients, 16 of whom presented a severe phenotype with extremely high total cholesterol (mean value of $321.6 \pm 66.0 \mathrm{mg} / \mathrm{dl}$, mean age $48.6 \pm 12.9$ ) and premature heart disease as well as strong family history and will therefore be candidates for mutations in other genes. The remaining 72 patients, 28 children and 44 adults, did not present with premature CHD but had severe hypercholesterolaemia (children mean total cholesterol value of $255.9 \pm 29.9$, mean age $10.0 \pm 4$; adults, mean total cholesterol value of

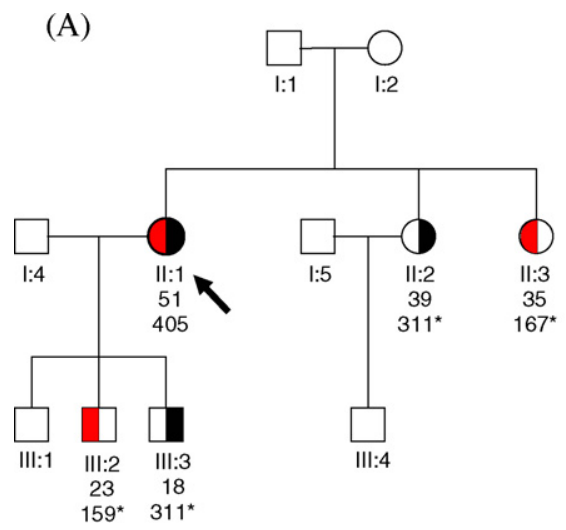

(B)

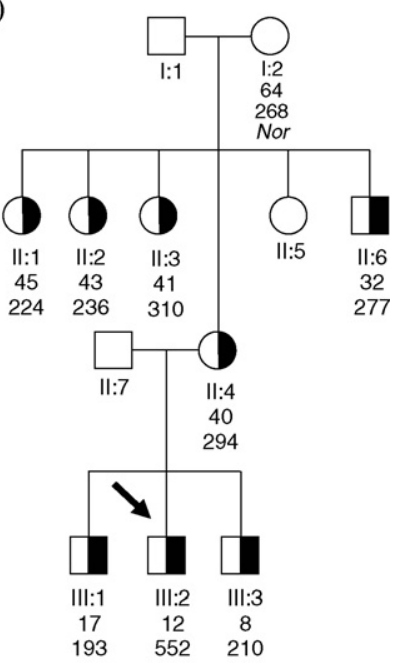

(C)

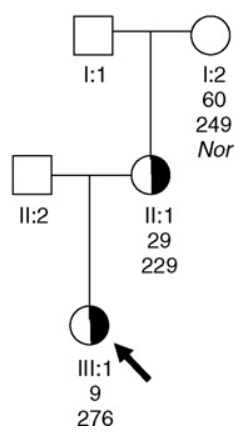

(D)

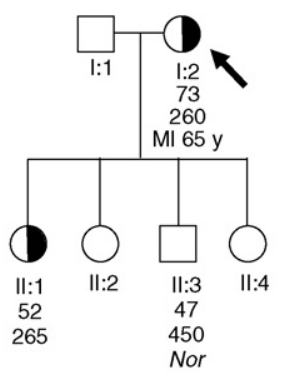

Fig. 2. Pedigrees of families where a putative alteration in the LDLR was found but does not co-segregate with the hypercholesterolaemia in the family. The arrow indicates the index patient. Age in years and total cholesterol values in $\mathrm{mg} / \mathrm{dL}$ (*correspond to values on treatment) are shown below each symbol. Half shaded symbols represent heterozygous individuals for the alteration found. Open symbols represent individuals where the alteration was not found (Nor) or individuals who were not screened. (A) Pedigree of the familiy of the index patient with the G248D (half shaded red) and 818 -2 A/G mutation (half shaded black) G248D is found in two normolipidaemic individuals and on none of the hypercholesterolaemic individuals. (B) Pedigree of the familiy of the index patient with the $1061-8 \mathrm{~T} / \mathrm{C}$ (half shaded black) alteration. The hypercholesterolaemic grandmother (I:2) does not have the alteration and the grandfather is normolipidaemic as far as we know. (C) Pedigree of the family of the index patient with the V838M (half shaded black) alteration. The hypercholesterolaemic grandmother (I:2) does not have the alteration and the grandfather is normolipidaemic as far as we know. (D) Pedigree of the family of the index patient with the $1359-5 \mathrm{C} / \mathrm{G}$ (half shaded black) alteration. The hypercholesterolaemic son (II:3) does not have the alteration. (For interpretation of the references to color in this figure legend, the reader is referred to the web version of the article.) 
Table 3

Clinical and molecular characteristics of Portuguese FH homozygous

\begin{tabular}{|c|c|c|c|c|c|c|c|c|c|c|c|c|}
\hline Subject & Mutations & Age & Sex & BMI & Lipid values & $\mathrm{TC}$ & LDL-c & HDL-c & TG & Apo A-I & Apo B & Clinical data \\
\hline 1 & {$[\mathrm{~V} 408 \mathrm{~L}]+[\mathrm{V} 408 \mathrm{~L}]$} & 55 & F & 23.2 & $\begin{array}{l}\text { w/o treat } \\
\text { On treat }\end{array}$ & - & - & $\begin{array}{l}- \\
47\end{array}$ & - & $\begin{array}{l}- \\
100.0\end{array}$ & $\begin{array}{l}- \\
139.0\end{array}$ & Stenosis \\
\hline 2 & {$[\mathrm{~A} 410 \mathrm{~T}]+[313+6 \mathrm{C}>\mathrm{T}]$} & 36 & $\mathrm{~F}$ & 30.4 & $\begin{array}{l}\text { w/o treat } \\
\text { On treat }\end{array}$ & $\begin{array}{l}490 \\
377\end{array}$ & $\begin{array}{l}435 \\
298\end{array}$ & $\begin{array}{l}42 \\
51\end{array}$ & $\begin{array}{l}64 \\
142\end{array}$ & $\begin{array}{l}117.0 \\
132\end{array}$ & $\begin{array}{l}245.7 \\
187.3\end{array}$ & - \\
\hline 3 & {$[\mathrm{~A} 410 \mathrm{~T}]+[\mathrm{A} 410 \mathrm{~T}]$} & 25 & $\mathrm{~F}$ & 18.5 & $\begin{array}{l}\text { w/o treat } \\
\text { On treat }\end{array}$ & $\begin{array}{l}596 \\
370\end{array}$ & $\begin{array}{l}512 \\
299\end{array}$ & $\begin{array}{l}65 \\
54\end{array}$ & $\begin{array}{l}96 \\
84\end{array}$ & $\begin{array}{l}- \\
119.0\end{array}$ & $\begin{array}{l}- \\
156.9\end{array}$ & - \\
\hline 4 & $\mathrm{H} 190 \mathrm{D}+\mathrm{K} 372 \mathrm{fs} X 392+\mathrm{A} 585 \mathrm{~S}^{\mathrm{a}}$ & 29 & M & 25.1 & $\begin{array}{l}\text { w/o treat } \\
\text { On treat }\end{array}$ & $\begin{array}{l}561 \\
346\end{array}$ & $\begin{array}{l}515 \\
298\end{array}$ & - & $\overline{9}$ & $-\overline{86.0}$ & $\begin{array}{l}- \\
189.3\end{array}$ & $\begin{array}{l}\text { MI, } 23 \text { years CABG, } \\
\text { CA, } 24 \text { years }\end{array}$ \\
\hline
\end{tabular}

Treat, treatment; TC, total cholesterol; TG, triglycerides; all lipids values are given in mg/dl. MI, myocardial infarction; CABG, coronary artery bypass graft; CA, coronary angioplasty.

a Parents were not available for testing so it could not be determined which mutations were in the same allele.

(A)
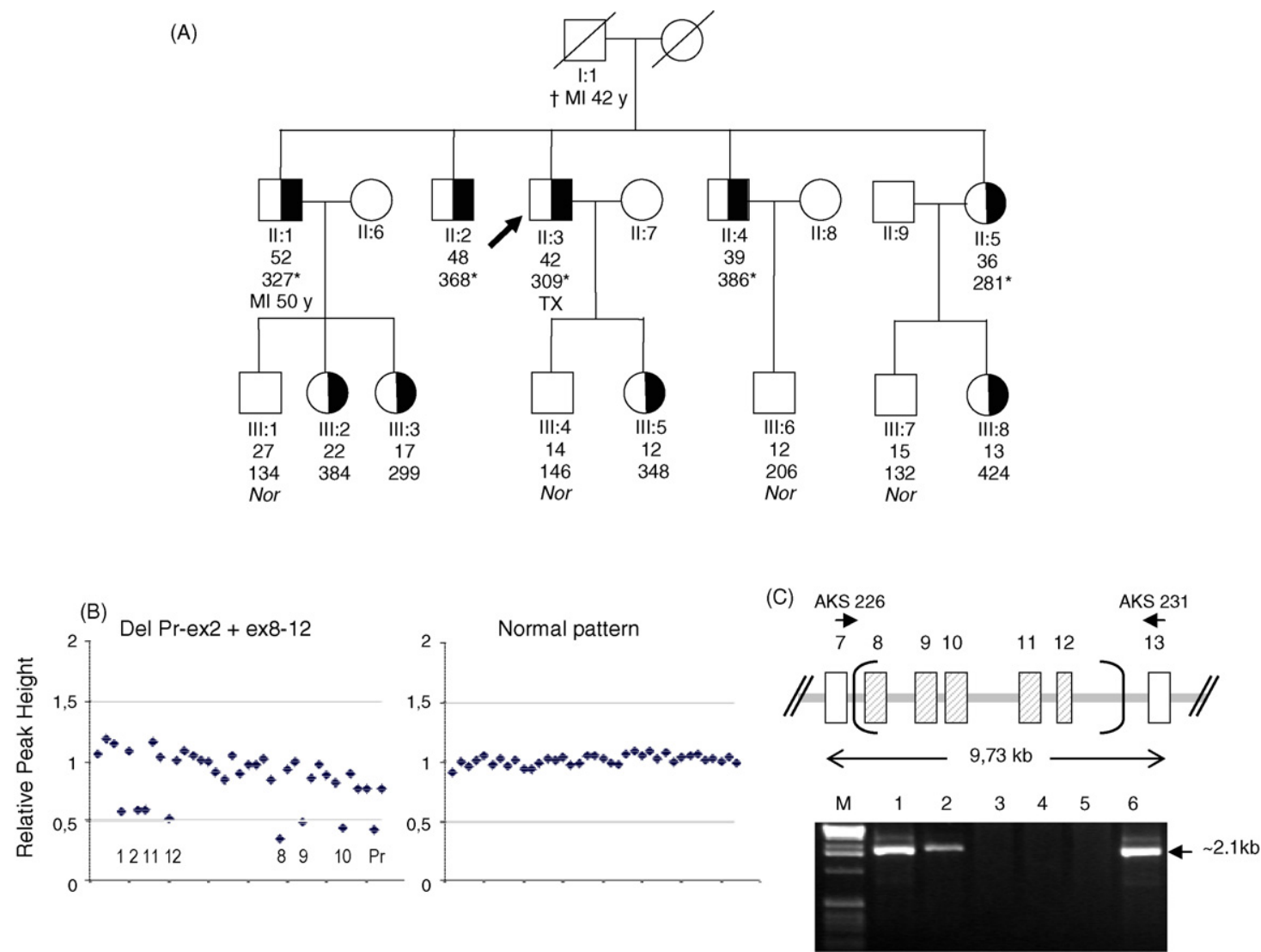

Fig. 3. Proband pedigree, mutation detection by MLPA and confirmation by PCR amplification. (A) Proband pedigree. The arrow indicates the index patient. Age in years and total cholesterol values in $\mathrm{mg} / \mathrm{dL}$ (*correspond to values on treatment) are shown below each symbol. Half shaded black symbols represent heterozygous individuals for the deletion of promoter + exons 1-2 and 8-12. Open symbols represent normolipidaemic individuals (Nor) where the mutation was not found or individuals who were not screened. (B) After normalization of all the peak heights relative to control samples, the normal height of each peak, corresponding to the amplification product of all the exons of the LDLR gene and several control sequences, is $\sim 1$. If the gene has a large rearrangement, such as the deletions found in this patient, the relative height of the peak drops to $\sim 0.5$. (C) Long PCR amplification of a fragment comprising exon 7-exon 13 . The fragment obtained for index patient and affected relatives with the deletion of exons $8-12$ was $\sim 2.1 \mathrm{~kb}$ and the normal allele was not amplified (9.73 kb). M, 1 kb ladder; lane 1, index patient (II:3, 20042); lane 2, relative III:5, lane 3, relative III:4; lane 4, relative III:6; lane 5, relative III:7; lane 6, relative III:8. Abbreviations: $\dagger$, deceased; MI, myocardial infarction; TX, tendon xanthomas. 
$343.6 \pm 64.4$, mean age $47.2 \pm 11.2$ ) and a family history of increased cholesterol values, consistent with a genetic disorder of lipid metabolism.

\subsection{Statistical analysis}

Only patients with an LDLR mutation were considered for this analysis.

\subsubsection{Comparison by mutation, age, sex and CHD occurrence}

The statistical analysis revealed that patients with mutations that lead to mRNA instability (stop codons, frameshift mutations, large deletions and splicing mutations) have higher total cholesterol values $(p=0.025)$ than patients with missense mutations, but there was no significant effect of mutation type or (age-adjusted) plasma cholesterol levels on incidence of CHD.

When the adult population was compared between sexes, it was observed that a higher percentage of males were smokers $(p=0.006)$ and a higher percentage of males presented with CHD $(p=0.042)$. Female FH patients with CHD were older $(p=0.004)$ and had higher Lp(a) values $(p=0.039)$ than FH females without $\mathrm{CHD}$ and the same was seen in the male group ( $p=0.022 ; p=0.048)$.

There were no significant differences in biochemical characteristics between sexes in the paediatric group.

\subsubsection{Comparison between countries}

Age, BMI, total cholesterol values, LDL cholesterol values, $\%$ of patients with premature CHD and $\%$ of patients with tendon xanthomas were compared between Portugal and Spain and between Portugal and the UK. Spanish values were obtained from the literature [10] and UK data was kindly provided by Dr R. Naoumova, Hammersmith Hospital Lipid Clinic. There were no significant biochemical differences between FH patients from Portugal and Spain except for total cholesterol values which are higher in Spanish women than in Portuguese women. Perhaps more surprising, FH patients in the UK do not exhibit higher values of total or LDL cholesterol than Portuguese patients and do not have a higher incidence of CHD than Portuguese or Spanish FH patients. This is despite a higher occurrence of tendon xanthomas in the UK, present in only $8.5 \%$ of Portuguese FH patients, $22.5 \%$ of Spanish FH patients and 78.8\% of English FH patients, although the mean age of the UK patients was significantly greater than the Portuguese $(56.8 \pm 17.1$ versus $48.7 \pm 14.2$ ).

\section{Discussion}

A network of lipid clinics was established for the Portuguese FH study and we regularly receive samples for this study. A genetic defect was identified in 88 patients with $\mathrm{FH}$, of whom 79 were heterozygous for a mutation in the $L D L R$, two were true homozygous and two were compound heterozygous for two different alleles, three were heterozygous for the $\mathrm{APOB}_{3500}$ mutation and two for a novel mutation in the PCSK9. These patients represent approximately $50 \%$ of the clinical FH patients referred to our study. Twenty-three mutations in the LDLR gene and the mutation in the PCSK9 gene have not been reported before, being until date, exclusive to the Portuguese population as far as we know. Family studies lead to the additional identification of 116 affected relatives, increasing the number of $\mathrm{FH}$ patients identified genetically to 204 .

The majority of the described alterations, specially the point mutations, fulfilled all the accepted criteria for a functional mutation [11] except the functional studies that are still being performed for the few exceptions. Additionally, four alterations were found in eight patients but were not considered mutations causing disease, since they did not cosegregate in the families with the hypercholesterolaemia or were alterations in non-coding regions close to the intron exon junction that potentially affect splicing. These four putative functional alterations are under investigation. Cosegregation of the mutation with the hypercholesterolaemia in the families studied was always a strong criteria that has been followed by our group and a report has only been sent to the assistant clinician when relatives were available to confirm this. Other mutations have been described as fulfilling almost all Cotton criteria and subsequently proven not to be a functional mutation [12] similarly to one of our index cases (Fig. 2A), so all attention has to be given to mutations that do not fulfil all these criteria and functional studies should be performed. Unfortunately only a few, for example A410T [13] or $313+1$ [14] have been proved by independent functional studies to be the causal mutation.

The importance of always studying the whole gene was also supported by one of the cases presented (Fig. 2A) where the first mutation found did not co-segregate with hypercholesterolaemia in the family, but when the whole gene was studied a splice site mutation was found that co-segregated with the phenotype in the family. However, the first alteration found in this family (G248D) that was not considered to be the mutation causing disease, was also found in other three unrelated FH families without any other detectable defect in the three genes studied. Thus it is possible that this mutation could have a mild effect and functional studies are being performed.

Based on the estimated frequency of homozygous FH in Europe (about one in a million) [1], Portugal should have about 10 homozygous patients, but to our knowledge, none have been described. Four patients have been identified in our study with two defective alleles of the LDLR but only one presented with a typical homozygous phenotype. For one of the compound heterozygous patients, there is an explanation, since it was observed that the mutation in the donor splice site appears to result in mis-splicing of only a small portion of the mRNA from that allele (data to be reported elsewhere). For the patient homozygous for V408L, the only explanation 
is that some modulation by environmental and genetic factors produces the less severe phenotype and for the patient homozygous for the A410T perhaps CHD has not yet developed due the young age of this patient. In fact the only patient with a typical homozygous phenotype only developed CHD at age 22 and smoked 20 cigars per day.

Several distinct mutations were found in our population, as seen in most European countries, but few alterations occurred more than once. All these more frequent mutations were found in apparently unrelated index patients but several haplotype analysis revealed evidence for a common ancestor. The haplotype analysis of the 11 patients carrying the A410T, the most frequent mutation accounting for $13 \%$ of all mutations found, showed that this mutation could have occurred twice since only two different haplotypes were found. Also the majority of these patients come from the same region in the south, which could imply that these patients must have a common ancestor. Since all patients with del exon 8-12 share the same haplotype it could be possible that they share a common ancestor and that the promoter region plus exons 1 and 2 deletion occurred subsequently on the allele already carrying the exon 8-12 deletion. The patients carrying the D203N probably have a common ancestor since the patients or their parents come from the same village in the Algarve and a family connection was subsequently revealed between three of these patients. The existence of a few common mutations would help the establishment of a rapid genetic diagnosis for FH in Portugal, but insufficient patients have yet been studied to determine correctly the frequency of these most common mutations.

Interestingly only four mutations were found in common with the Spanish FH population, namely M-21L [15], S156L [16], D200G [17], and G322S [18] and this last one also with the Brazilian population [19]. From the available literature it seems that not enough FH patients have been studied in these three countries for results in the populations to be compared. Castillo and co-workers [20] described 13 Spanish patients with the $\mathrm{APOB}_{3500}$ mutation, 11 coming from a region just north of Portugal. Surprisingly our three patients are from a central region of Portugal and share the same haplotype.

In two unrelated patients a mutation was identified in the PCSK9 gene, as well as in one relative. All these patients presented a very severe phenotype with premature CHD, as other patients with similar PCSK9 mutations [9]. The mutation described, D374H has not been described before although, another nucleotide change has been described in the same codon (D374Y) [21] that is accepted as a functional mutation $[22,23]$.

It was not possible to identify a mutation in any of the three genes analysed in about $50 \%$ of the clinical FH patients studied, although 16 presented a severe phenotype with very high total cholesterol values and premature CHD. Other genetic causes for hypercholesterolaemia have to be sought and therefore these patients will be good candidates for other gene defects yet to be known to be involved in FH. The most interesting patients belong to the paediatric group since in these patients, hypercholesterolaemia due to environmental factors can be more easily ruled out. The possibility that a mutation in the studied genes could have been missed must be considered since no method is $100 \%$ effective.

To determine if the phenotype of Portuguese FH patients resembles that of a group of FH patients from Spain, a neighbouring country with shared ancestors and culture, first of all the lipid profile of these two general populations was compared. Surprisingly, this revealed that total mean cholesterol in the Spanish population is significantly lower than in the Portuguese, that is $4.9 \mathrm{mmol} / \mathrm{l}$ versus $5.5 \mathrm{mmol} / \mathrm{l}$ for men and $5.0 \mathrm{mmol} / \mathrm{l}$ versus $5.5 \mathrm{mmol} / 1$ for women [24,25]. In contrast, the values for the Portuguese population are very similar to the ones found in the English population, $5.5 \mathrm{mmol} / \mathrm{l}$ for male and $5.6 \mathrm{mmol} / \mathrm{l}$ for women [26] despite it being a north European country with a distinct geography and culture from Portugal. Thus it seemed less certain that Portuguese and Spanish FH patients would be similar. However, when the clinical characteristics of Portuguese and Spanish FH patients were compared there were no statistically significant differences in age, BMI, pre-treatment total cholesterol (except for women), LDLc and percentage of patients with CHD. The Portuguese FH patients were also compared to a group of English FH patients from the Hammersmith Hospital Lipid Clinic and the only significant difference observed was a higher percentage of patients with tendon xanthomas in English FH patients. However the similarity of the clinical characteristics of $\mathrm{FH}$ patients of these three countries with different backgrounds could be limited in this analysis because the numbers of these three groups of patients are very different. Since there are no differences in mean lipid levels in the FH population between these three countries, two alternative explanations could be advanced to explain the fact that UK FH patients have such a high percentage of tendon xanthomas; either tendon xanthomas are not being well diagnosed in Portugal or Portuguese FH patients are less susceptible to the development of tendon xanthomas for some environmental reason. The first explanation seems to be more plausible since a more recent publication [27] showed that $40 \%$ of Spanish FH patients had tendon xanthomatosis when tendon ultrasonography was used to analyse Achilles tendon xanthomas.

FH fulfils the World Health Organization criteria for screening programs [28]. Since the introduction of statins (HMG-CoA reductase inhibitors), in the last decade, the prognosis of $\mathrm{FH}$ patients has improved substantially and therefore it is considered appropriate to do a systematic screening for $\mathrm{FH}$ [29] and there are no negative ethical implications in the study of this disorder. Nevertheless FH is severely under-diagnosed in Portugal, this being the first clinical and molecular study of FH in this country. The number of FH patients studied is still very small but steps are now being undertaken to increase this number, namely a collaboration with the Portuguese Cardiology Society that will allow, in the next 3 years, the complete study of 300 new families with FH. After the national publication of this study [3], our NHS 
has become aware of the importance of early identification of this disorder as part of a programme for the prevention of premature CHD and has given its scientific support to the Portuguese FH Study.

The newly identified FH patients are now receiving counselling and treatment based on the genetic diagnosis and it is expected that some of the younger patients may not develop premature $\mathrm{CHD}$ due to the early identification of their disease through this study. The present study also helped to establish the appropriate therapeutic regime for each patient. None of the patients ceased their medication because a mutation was not found in the LDL receptor gene, but several patients in whom a mutation was found were treated subsequently with a more aggressive therapeutic regime.

\section{Acknowledgements}

We would like to thank the Clinical Chemistry lab at the National Institute of Health, Lisbon for performing the biochemical tests, Sara Rabiais and Eleonora Paixão (ONSA, INSA) for help with the statistical analysis and Dr. Naoumova for the access to the Hammersmith Lipid Clinic patients data for comparison. We are indebted to all index patients and relatives for participating in this study. We would also like to acknowledge the following grants: Praxis XXI/BD/15071/98 (M. Bourbon, PhD grant), Comissão de Fomento da Investigação em Cuidados de Saúde 2000-2001 (1 year project grant), INSA BIC 04/2003-II (AC Alves, research grant).

\section{References}

[1] Goldstein JL, Hobbs H, Brown MS. Familial hypercholesterolemia. In: Scriver CR, Beaudet AL, Sly WS, Valle D, editors. The metabolic and molecular bases of inherited disease. 7th ed. New York: McGraw-Hill; 1995. p. 1981-2030.

[2] Neil HA, Huxley RR, Hawkins MM, Durrington PN, Betteridge DJ, Humphries SE. Comparison of the risk of fatal coronary heart disease in treated xanthomatous and non-xanthomatous heterozygous familial hypercholesterolaemia: a prospective registry study. Atherosclerosis 2003;170(1):73-8.

[3] Bourbon M, Rato Q, on behalf of the investigators of the Portuguese FH Study. Portuguese Familial Hypercholesterolaemia Study. Rev Port Cardiol 2006;25(11):999-1013.

[4] Scientific Steering Committee on behalf of the Simon Broome Register Group. Risk of fatal coronary heart disease in familial hypercholesterolaemia. BMJ 1991;303(6807):893-6.

[5] Fouchier SW, Kastelein JJ, Defesche JC. Update of the molecular basis of familial hypercholesterolemia in The Netherlands. Hum Mutat 2005;26(6):550-6.

[6] Abifadel M, Varret M, Rabes JP, et al. Mutations in PCSK9 cause autosomal dominant hypercholesterolemia. Nat Genet 2003;34(2):154-6.

[7] Ludwig EH, McCarthy BJ. Haplotype of the human apolipoprotein B mutation associated with familial defective apolipoprotein B100. Am J Hum Genet 1990;47:712-20.

[8] Myant NB, Gallagher JJ, Knight BL, et al. Clinical signs of familial hypercholesterolemia in patients with familial defective apolipoprotein B-100 and normal low density lipoprotein receptor function. Arterioscler Thromb 1991;11(3):691-703.
[9] Naoumova RP, Tosi I, Patel D, et al. Severe hypercholesterolemia in four British families with the D374Y mutation in the PCSK9 gene longterm follow-up and treatment response. Arterioscler Thromb Vasc Biol 2005;25:2654-60.

[10] Mata P, Alonso R, Castillo S, Pocovi M. Spanish Group of Familial Hypercholesterolemia. MEDPED and the Spanish Familial Hypercholesterolemia Foundation. Atheroscler Suppl 2002;2(3):9-11.

[11] Cotton RG, Scriver CR. Proof of "disease causing" mutation. Hum Mutat 1998;12(1):1-3.

[12] Naoumova RP, Neuwirth C, Pottinger B, Whittal R, Humphries SE, Soutar AK. Genetic diagnosis of familial hypercholesterolaemia: a mutation and a rare non-pathogenic amino acid variant in the same family. Atherosclerosis 2004;174(1):67-71.

[13] Chang JH, Pan JP, Tai DY, et al. Identification, characterization of LDL receptor gene mutations in hyperlipidemic Chinese. J Lipid Res 2003;44(10):1850-8.

[14] Sun XM, Patel DD, Bhatnagar D, Knight BL, Soutar AK. Characterization of a splice-site mutation in the gene for the LDL receptor associated with an unpredictably severe clinical phenotype in English patients with heterozygous FH. Arterioscler Thromb Vasc Biol 1995;15(2): 219-27.

[15] Garcia-Garcia AB, Real JT, Puig O, et al. Molecular genetics of familial hypercholesterolemia in Spain: ten novel LDLR mutations and population analysis. Hum Mutat 2001;18(5):458-9.

[16] Mozas P, Cenarro A, Civeira F, Castillo S, Ros E, Pocovi M. Mutation analysis in 36 unrelated Spanish subjects with familial hypercholesterolemia: identification of 3 novel mutations in the LDL receptor gene. Hum Mutat 2000;15(5):483-4.

[17] Cenarro A, Jensen HK, Casao E, et al. Identification of recurrent and novel mutations in the LDL receptor gene in Spanish patients with familial hypercholesterolemia. Mutations in brief no. 135. Online. Hum Mutat 1998;11(5):413.

[18] Mozas P, Castillo S, Tejedor D, et al. Molecular characterization of familial hypercholesterolemia in Spain: identification of 39 novel and 77 recurrent mutations in LDLR. Hum Mutat 2004;24(2):187.

[19] Salazar LA, Hirata MH, Cavalli SA, et al. Molecular basis of familial hypercholesterolemia in Brazil: identification of seven novel LDLR gene mutations. Hum Mutat 2002;19(4):462-3.

[20] Castillo S, Tejedor D, Mozas P, et al. The apolipoprotein B R3500Q gene mutation in Spanish subjects with a clinical diagnosis of familial hypercholesterolemia. Atherosclerosis 2002;165(1):127-35.

[21] Leren TP. Mutations in the PCSK9 gene in Norwegian subjects with autosomal dominant hypercholesterolemia. Clin Genet 2004;65(5):419-22.

[22] Sun XM, Eden ER, Tosi I, et al. Evidence for effect of mutant PCSK9 on apolipoprotein B secretion as the cause of unusually severe dominant hypercholesterolaemia. Hum Mol Genet 2005;14(9):1161-9.

[23] Horton JD, Cohen JC, Hobbs HH. Molecular biology of PCSK9: its role in LDL metabolism. Trends Biochem Sci 2007;32(2):71-7.

[24] Gomez-Gerique JA, Gutierrez-Fuentes JA, Montoya MT, et al. Perfil lipidico de la poblacion espanola: estudio DRECE (Dieta y Riesgo de Enfermedad Cardiovascular en Espana) (Article in Spanish). Medicina Clinica (Barcelona) 1999;113:730-5.

[25] Caracterização do perfil lipídico da populacão portuguesa. Pamphlet: Becel Institute; 2001.

[26] Health survey for England. Risk factors for cardiovascular disease. UK Department of Health; 2003.

[27] Junyent M, Cofan M, Nunez I, Gilabert R, Zambon D, Ros E. Influence of HDL cholesterol on preclinical carotid atherosclerosis in familial hypercholesterolemia. Arterioscler Thromb Vasc Biol 2006;26(5):1107-13.

[28] WHO, Human Genetics DoNDP. Familial hypercholesterolaemia: report of a second WHO Consultation. Geneve: WHO, 1999.

[29] Marks D, Wonderling D, Thorogood M, Lambert H, Humphries SE, Neil HA. Screening for hypercholesterolaemia versus case finding for familial hypercholesterolaemia: a systematic review and costeffectiveness analysis. Health Technol Assess 2000;4(29):1-123. 